\title{
Unique surface and internal structure of struvite crystals formed by Proteus mirabilis
}

\author{
Jolanta Prywer $\cdot$ Agnieszka Torzewska • \\ Tomasz Płociński
}

Received: 24 May 2012/ Accepted: 2 August 2012/Published online: 22 August 2012

(C) The Author(s) 2012. This article is published with open access at Springerlink.com

\begin{abstract}
Crystallization of struvite from artificial urine in the presence of Proteus mirabilis microorganisms depends strongly on $\mathrm{pH}$ value. At small value of $\mathrm{pH}$, struvite yields crystals of coffin-like habit with very specific structure. The analysis using scanning electron microscopy shows that the crystals possess well-defined faces, but higher magnifications show very specific structuration as if the crystals were built from small three-dimensional subunits. The possible role of microorganisms in the formation of such a structuration is analyzed. At higher $\mathrm{pH}$ value, the crystals exhibit dendritic growth with main trunk and branches. Although the formation mechanism of the specific structuration as well as dendritic structures is unknown, the nature of forces for such an alignment is analyzed. The revealed porous internal structure of struvite is also analyzed. The investigations provide evidence for the importance of biological regulation in crystallization process.
\end{abstract}

Keywords Infectious urinary stones - Struvite · Crystal growth $\cdot$ Proteus mirabilis

\footnotetext{
J. Prywer $(\square)$

Institute of Physics, Technical University of Lodz, ul. Wólczańska 219, 93-005 Lodz, Poland

e-mail: jolanta.prywer@p.lodz.pl

\section{A. Torzewska}

Department of Immunobiology of Bacteria, Institute of Microbiology and Immunobiology,

University of Lodz, ul. Banacha 12/16, 90-237 Lodz, Poland

T. Płociński

Faculty of Materials Science and Engineering,

Warsaw University of Technology, ul. Wołoska 141,

02-507 Warsaw, Poland
}

\section{Introduction}

Magnesium ammonium phosphate hexahydrate, $\mathrm{MgNH}_{4}$ $\mathrm{PO}_{4} \cdot 6 \mathrm{H}_{2} \mathrm{O}$, known as struvite is an inorganic material whose crystallization is more and more wider investigated for several reasons. Struvite can be a problem in sewage and wastewater treatment as it precipitates easily on points with high turbulence such as elbows of pipe connections, valves, aeration assemblies and pump internal components exposed to wastewater [1,2]. At these places, struvite may grow rapidly leading to system pipe clogging. On the other hand, struvite is a potential source of phosphorus, nitrogen and magnesium, and therefore it is the main compound recovered from wastewater and recycled as a useful $\mathrm{P}-\mathrm{N}-$ Mg-containing fertilizer [3, 4].

The second and the most important reason for which struvite is widely investigated is the fact that it is the main component of so-called infectious urinary stones [5]. It is formed when the urinary tract is infected by urease positive microorganisms, mainly from Proteus sp. Urease, an enzyme produced by these microorganisms, splits urea, $\left(\mathrm{NH}_{2}\right)_{2} \mathrm{CO}-\mathrm{a}$ natural component of urine-into ammonia $\mathrm{NH}_{3}$ and carbon dioxide $\mathrm{CO}_{2}$. These products alkalinize urine. Under alkaline conditions, an increase in the concentration of the $\mathrm{NH}_{4}{ }^{+}, \mathrm{CO}_{3}{ }^{2-}$ and $\mathrm{PO}_{4}{ }^{3-}$ ions occurs. These ions, together with $\mathrm{Mg}^{2+}$ ions physiologically present in the urine, favor the crystallization of struvite. Struvite formation is usually associated with the precipitation of carbonate apatite $\left[\mathrm{CA}, \mathrm{Ca}_{10}\left(\mathrm{PO}_{4}\right)_{6} \mathrm{CO}_{3}\right]$, because the $\mathrm{Ca}^{2+}$ ions are present in the urine. This component precipitates in an amorphous form. Struvite together with small amount of CA (up to $10 \%$ ) forms the so-called infectious stones. Since urinary stones are identified according to the predominant mineral present in their composition, these infectious stones are also called struvite 
stones. This kind of stones constitutes from $10 \%$ [5] to $30 \%[6,7]$ of all urinary stones. The frequency of their occurrence depends on the country and the degree of its industrialization. They are found more frequently in economically developed countries. It seems that this must be attributed to the different lifestyles and dietary habits. Struvite stones may grow rapidly and, if not adequately treated, can develop into a large stone that fills the entire intra-renal collecting system. Patients with infectious stones left untreated have about a $50 \%$ chance of losing a kidney $[6,8,9]$.

In view of the above reasons, struvite crystallization has been increasingly investigated over the last years. Preliminary investigations demonstrate that struvite crystals grown in in vitro conditions in the presence of microorganisms have well-defined faces, but they show very specific structures and appear like built from small subunits $[10,11]$. Moreover, gaps between small units from which the crystal is built may be identified, suggesting the porous nature of struvite. Porosity and small building units may suggest that struvite is mesocrystal [12].

In this paper, we analyze in detail the specific structuration of struvite, its morphology and habit modification and the role of microorganisms in this structuration. For this purpose, we performed sets of experiments of struvite crystallization from artificial urine. The crystallization process was induced by $P$. mirabilis to mimic the real urinary tract infection, which usually leads to urinary stone formation.

\section{Materials and methods}

Proteus mirabilis strain was isolated from human urinary stone. Before the crystal growth experiment, bacteria were maintained on a slant of tryptic soy agar overnight at $37{ }^{\circ} \mathrm{C}$ and then suspended in artificial urine to the concentration of $5 \times 10^{5} \mathrm{CFU} / \mathrm{ml}$.

The artificial urine used during crystal growth experiments was made from the following components [13] (g/l): $\mathrm{CaCl}_{2} \cdot 2 \mathrm{H}_{2} \mathrm{O}, 0.651 ; \mathrm{MgCl}_{2} \cdot 6 \mathrm{H}_{2} \mathrm{O}, 0.651 ; \mathrm{NaCl}, 4.6$; $\mathrm{Na}_{2} \mathrm{SO}_{4}, 2.3 ; \mathrm{KH}_{2} \mathrm{PO}_{4}, 2.8 ; \mathrm{KCl}, 1.6 ; \mathrm{NH}_{4} \mathrm{Cl}, 1.0$; sodium citrate, 0.65 ; sodium oxalate, 0.02 ; urea, 25.0; creatine, 1.1; and tryptic soy broth, 10.0. All chemicals were purchased from Sigma and were used without further purification. The tryptic soy broth was added to stimulate the bacterial growth, but not anticipated to interfere with the precipitation process and does not sequester constituent ions of the precipitating crystalline and amorphous phases.

Mineral components in the above artificial urine correspond to mean concentration found in $24 \mathrm{~h}$ period in normal human urine. Crystallization occurs after addition of the suspension of bacteria and incubation at $37^{\circ} \mathrm{C}$. The crystallization process occurs at conditions emulating the natural conditions existing in human body during the infection by Proteus sp. The experimental procedure is described in detail elsewhere $[9,14]$. Control experiments without bacteria were performed using artificial urine of the same composition. In this case, the crystallization process occurs after consecutive addition of aqueous ammonia solution $(1 \mathrm{M})$ to mimic urease activity under the control of $\mathrm{pH}$ value.

The $\mathrm{pH}$ of the solution of artificial urine was screened along the experiments using digital $\mathrm{pH}$-meter (Elmetron CP-215). The initial $\mathrm{pH}$ of artificial urine was adjusted to a value of 5.8. During all the growth experiments, crystals samples were taken at regular intervals and observed by optical microscopy (Opta-Tech MN800) and scanning electron microscopy (SEM). The SEM micrographs were performed using a Vega $5135 \mathrm{MM}$-Tescan microscope. The internal structure of the investigated crystals was revealed with the aid of a focused ion beam (FIB) microscope (Hitachi FB-2100). In this system, a highly focused ion beam with beam diameter of $6 \mathrm{~nm}$ is applied. As the ion source liquid $\mathrm{Ga}^{+}$ions are applied.

Crystals were identified as struvite by X-ray diffraction (XRD), using X'pert PRO MPD (PANanalytical) diffractometer. The $\mathrm{Cu} \mathrm{K}_{\alpha}$ radiation monochromatized by nickel filter was applied. The X'pert HighScore Plus (PANanalytical) software was used to analyze XRD patterns. The crystals for XRD and FIB examination were separated from bacteria suspension and CA precipitation in sedimentation process - the settling process proceeds more rapidly for larger-sized particles.

\section{Results and discussion}

\section{Specific structuration of struvite}

Struvite belongs to the non-centrosymmetric point group $m m 2$ of the orthorhombic system with the space group $P m n 2_{1}$, with the lattice parameters [15]: $a=6.966(1) \AA$, $b=6.142(1) \AA$ and $c=11.217(2) \AA$.

In order to study the mineralization of struvite, we performed several sets of experiments of struvite crystallization from artificial urine with the presence of $P$. mirabilis. The results of our experiments are presented in Fig. 1 . Crystal morphology and growth process strongly depends on $\mathrm{pH}$ (Fig. 1), which increases with time because of urease activity. First single crystals appear approximately after $3 \mathrm{~h}$ at $\mathrm{pH}$ 7.2. With time and with increase in $\mathrm{pH}$, the amount of crystals is greater. The size of the largest crystals is about $60 \mu \mathrm{m}$ along the $a$ axis (the crystallographic directions are defined in Figs. 1, panel s1 and 6). The aspect ratio (AR) defined as the crystal length $l_{\mathrm{a}}$ along the 

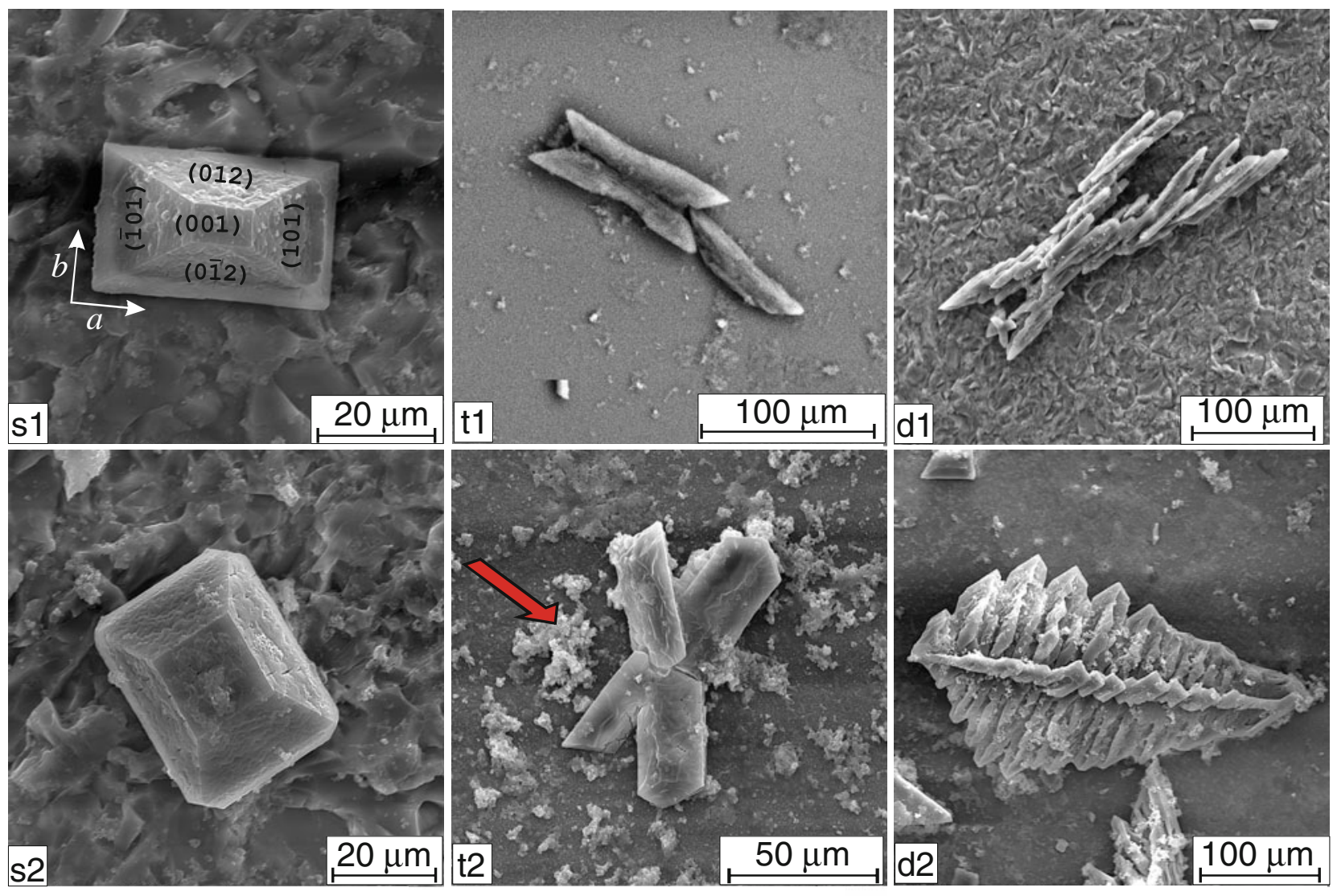
$7.2-9.0$
$9.0-9.5$
$3-5 h$
$5-8 h$

\section{5}

$8-24 h$

$\mathrm{pH}$ time $[\mathrm{h}]$
Fig. 1 SEM micrographs illustrating the dependence of morphology and habits of struvite on $\mathrm{pH}$ of artificial urine; left column: single hemimorphic crystals obtained for small $\mathrm{pH}$ values; middle column: contact $(t 1)$ and penetration ( $t 2)$ twins obtained for higher $\mathrm{pH}$ values; right column: $\mathrm{X}$-shaped $(d 1)$ and fern-leaf $(d 2)$ dendrite crystals obtained for the highest values of $\mathrm{pH}$; the image in $d 1$ panel is reproduced from Ref. [10]; arrow indicates CA precipitation

the adhesion is greater. In those places, bacteria or nucleus of crystalline phase can settle easier than in other places. Therefore, the sites of damaged epithelium, and consequently, dendritic structures can facilitate the nucleation process and promote the crystallization of struvite. In all photographs presented in Fig. 1, one may notice amorphous deposition of CA (arrow) which precipitates, in a small amount, as described in "Introduction".

From the enlarged pictures (Fig. 2), one may note that the faces of single crystals are well defined (Fig. 2, panels $\mathrm{L} 1, \mathrm{~L} 2)$, but it seems that the crystal is constructed from small subunits with average size of $1-3 \mu \mathrm{m}$. The picture L2 shows the rectangle area marked in L1 at a higher magnification. Another single crystal with such structure is shown in Fig. 2, L3. The rod-like structures visible here are bacteria. The picture L4 (Fig. 2) shows similar structure of the $(00 \overline{1})$ face (the bottom of the coffin-like habit) of struvite crystal. On the basis of Fig. 2, left column, gaps 

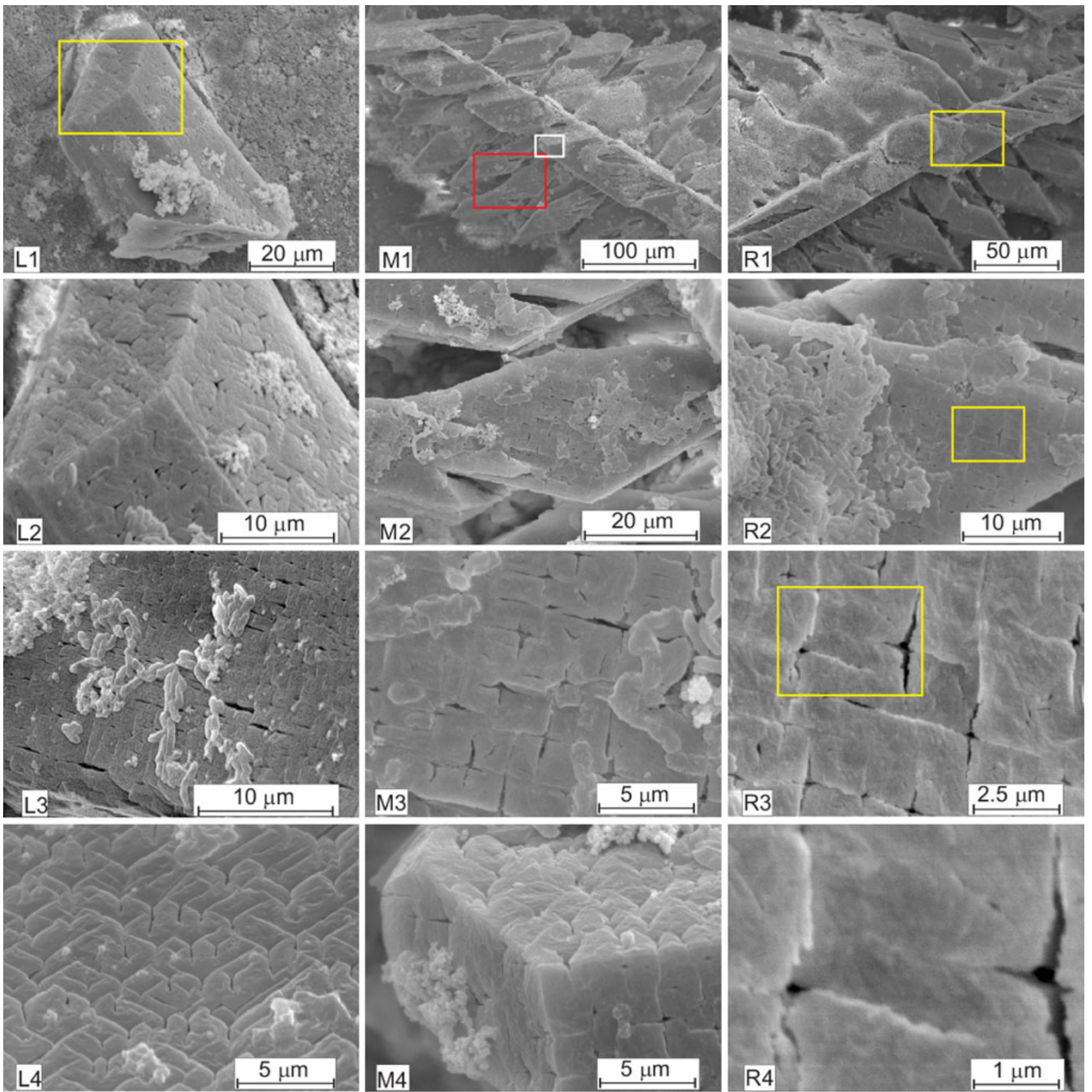

Fig. 2 SEM micrographs of struvite crystals at higher magnification revealing specific structuration of their surfaces; left column: single hemimorphic morphology, L2 is a higher magnification of rectangle area marked in L1; middle and right columns: dendrite-like structures; M2 and M4 are higher magnification of the rectangle areas marked in

between small units from which the crystal is built may be identified, suggesting the porous nature of struvite. The size of the gaps is in the range from tens to hundreds of nanometres. The size of the largest gaps is about $500 \mathrm{~nm}$. These results are consistent with the results presented in [9, $10,19]$ and may suggest that struvite is a mesocrystal. However, predominantly, mesocrystals are aggregates of
M1 by colors red and white, respectively; $M 3$ is higher magnification of the rectangle area marked in $M 2 ; R 2, R 3$ and $R 4$ are higher magnification of the rectangle areas marked in $R 1, R 2$ and $R 3$, respectively

nanoparticles and therefore the results may suggest that our case is borderline case.

When $\mathrm{pH}$ value increases rapidly, the presence of single crystals vanishes progressively and the majority of the crystals are hopper and dendrite-like. In some cases, single, hopper and dendrite-like crystals have been observed coexisting. The hopper crystals correspond to an intermediate 

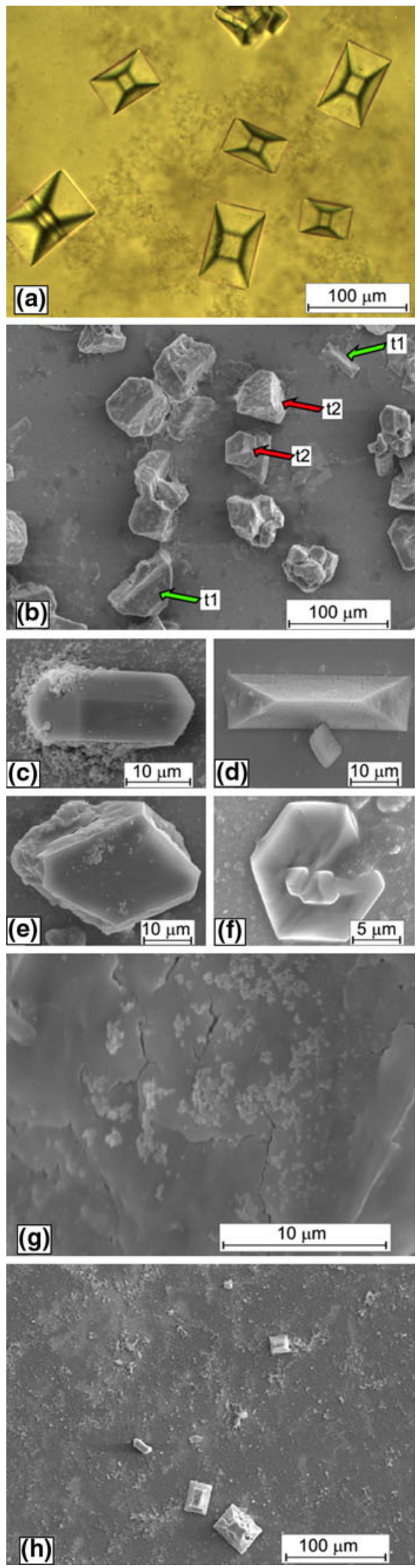

Fig. 3 Struvite crystals obtained $\mathbf{a}-\mathbf{f}$ in the control experiments without bacteria and $\mathbf{h}$ in the presence of bacteria; $\mathbf{g}$ struvite surface structure in the case of control experiment without bacteria; $t 1$ and $t 2$ in $\mathbf{b}$ indicate coffin-like and hexagonal habits, respectively

stage of evolution between the single and dendrite-like crystals. The evolution of dendrite-like crystals is mainly influenced by the rate of change in $\mathrm{pH}$ with minor influence of the value of $\mathrm{pH}$. The absence of dendrite-like structures is a key indication that sample did not experience a rapid change in $\mathrm{pH}$ value. The virtual boundary separating these two kinds of crystals (single and dendrite-like) can be considered as the limit between the slow and rapid growth. This finding is consistent with the investigations presented in Ref. [20], in which the authors state that the morphology of crystals and their aggregates reflect the rate of crystallization and suggest the mechanism of stone formation [20]. The obtained twins and dendritic structures are illustrated in Fig. 1, middle and right columns, respectively. Dendrites are $\mathrm{X}$-shaped (Fig. 1, panel d1) or they are composed of one trunk and branches symmetrically distributed on two sides of the trunk (Fig. 1, panel d2). All branches on one side of the trunk are parallel to each other and grow at an angle of $\sim 77^{\circ}$ with respect to the trunk. The branches are all located in the same plane. The magnified images (Fig. 2, middle and right columns) demonstrate that dendritic structures show the same characteristic structuration as in the case of single crystals. Picture M1 (Fig. 2) shows exemplifying dendritic structures. Pictures M2 and M4 show rectangle areas, red and white, respectively, marked in picture M1, at a higher magnification. Picture M3 is higher magnification of the rectangle area marked in M2. From these enlarged pictures, it may be observed clearly the characteristic pattern on the crystal surfaces. Picture M4 shows that this pattern is characteristic not only for a given surface but it is also characteristic for all surfaces. The right column of Fig. 2 (panels R1-R4) shows another example of dendritic structures with this characteristic structuration. Panels R2, R3 and R4 show rectangle areas marked in $\mathrm{R} 1, \mathrm{R} 2$ and $\mathrm{R} 3$ panels, respectively, at higher magnification. The example of this dendritic structure also shows characteristic pattern and demonstrates that the obtained structuration is not accidental.

In order to understand the role of $P$. mirabilis in the formation of struvite structuration, we investigated the crystallization of struvite in the absence of bacteria. Such investigations are necessary to prove that SEM images show real structures instead of drying artifacts that result from sample preparation. The results are presented in Fig. 3. In the absence of bacteria, a relatively large number of crystals are formed (Fig. 3a) compared with the case of the presence of bacteria (Fig. 3h). In the case of absence of bacteria, the number of crystals is increased and so is their 
size-compare Fig. 3a, h. In most cases, the crystals are of coffin-like habits (Fig. 3a), but the crystals of other habits are also observed but rarely (Fig. 3b-f). In particular, some of the crystals take hexagonal habits (Fig. 3b, f). None of the crystals shows the structuration observed in the case of the presence of bacteria. Even at high magnification (Fig. 3g), we do not observe the characteristic structuration, instead we can see cracks which probably follow from the fact that the crystals were in the vacuum. To be sure that in both cases, we deal with struvite we have done the XRD analysis. Figure 4 shows XRD patterns of the obtained precipitation in both cases: in the presence (pattern denoted by 1) and in the absence of bacteria (pattern denoted by 2). These patterns reveal that the $d$-spacings ( $2 \theta$ value) are the same for the important lines and are comparable with the reference data. Therefore, the XRD patterns confirm that the precipitation is struvite in both cases. From these results, it can be concluded that $P$. mirabilis play a crucial role in directing the characteristic struvite structuration. It is suggested that the extracellular matrices of microorganisms mainly composed of proteins, and polysaccharides play crucial role in this structuration. This matter requires further research and analysis. Very similar pattern of struvite crystals was observed by Chen et al. [11]. In the case of investigations presented in Ref. [11],

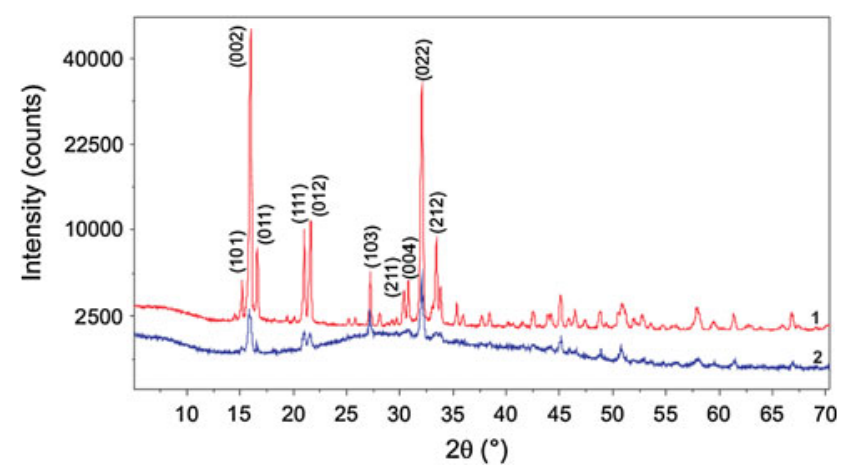

Fig. 4 XRD patterns of struvite grown from artificial urine with the presence (curve 1) and with the absence (curve 2) of P. mirabilis the crystals were grown in the presence of $P$. mirabilis in the appropriate solution which was not the solution of artificial urine. The observed surface pattern confirms that such a structuration is characteristic for the presence of bacteria.

It is interesting to know whether this structuration is characteristic for surfaces only or for bulk structure and whether the big crystals are built from small subunits. In order to find out this matter, we have investigated the crystals with FIB microscope. The results of these investigations are presented in Fig. 5. Figure 5a presents an aggregate of few struvite crystals of coffin-like habit with characteristic structure. One of the crystals forming this aggregate, the one marked by the arrow, is cut though with the aid of FIB microscope. The crystal was cut approximately in the half of its thickness, i.e. about $10 \mu \mathrm{m}$ from the external surface. Figure $5 \mathrm{~b}$ presents the obtained crosssection at the higher magnification. The revealed internal structure indicates that crystal is porous, with characteristic tubular pore structure. Most of these pores run inwards the crystal perpendicularly to external surfaces. The presence of such pores may suggest possible interaction of struvite stone with urine. Urine passing through and outside the crystals may enhance the absorption of other chemicals that can stimulate growth or aggregation of crystals. It can be also assumed that porosity of crystals facilitates bacterial adhesion and biofilm development, in which bacteria surrounded by exopolysaccharides are resistant to antibiotics and host immune defense mechanisms. This phenomenon may explain the rapid growth of infectious urinary stones, persistence and recurrence of this disease.

In addition, material porosity deteriorates its mechanical properties. This issue maybe very important in the case of applying the extracorporeal shock wave lithotripsy, ESWL, which is the most common urological procedure used to remove stones from the urinary tract. The porosity of material is correlated with a tendency to either ductility or brittleness and, consequently, may change the manner by which urinary stones interact with the mechanical stresses produced by ESWL. This is discussed in Ref. [21].
Fig. 5 Struvite crystals grown in the presence of $P$. mirabilis, one of the crystal marked in a by an arrow is cut though with the aid of FIB system; $\mathbf{b}$ the higher magnification of the rectangle area marked in a revealing the porous internal structure of struvite with tubular pores
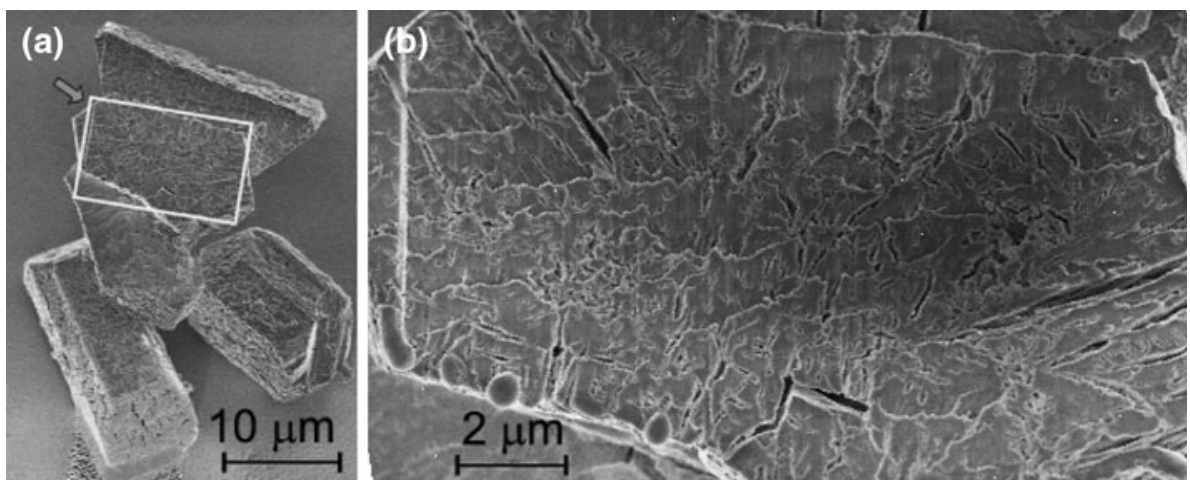
Moreover, the porosity is in agreement with the observations of natural struvite isolated from real urinary stones which are described as porous [19, 22]. However, the internal structure does not confirm good 3D arrangement of small subunits, nanoparticles or microparticles, as it might be suggested by surface pattern. Therefore, the obtained results do not confirm preliminary suggestion $[10,11]$, that struvite is mesocrystal. The conclusion from the current analysis is that the struvite crystals demonstrate characteristic pattern, which is surface pattern only.

\section{Struvite morphology and habit}

The morphology of crystals forming urinary stones is very important for several reasons. First of all, the morphology of crystals influences the sensitivity to the ESWL, reflects the rate of crystallization and suggests the mechanism of stone formation [20]. Moreover, the appearance of a particular morphology may be a significant indicator of a given disease, as the morphology is different for various diseases [19]. Therefore, in this subsection we focus in more detail on struvite morphology.

As we stated earlier, the morphology of struvite crystals and growth process strongly depend on $\mathrm{pH}$ value. Single crystals, which are characteristic for low $\mathrm{pH}$, are of coffinlike habit. The most basic crystal morphology is composed of the following faces: $(001),(00 \overline{1}),\{101\},\{10 \overline{1}\},\{011\}$, $\{012\}$, and $\{010\}$ [14]. Usually the $(00 \overline{1})$ face is larger than the opposite (001) face (Fig. 1, left column; Fig. 6a, b). The effect of different extension of the (001) and $(00 \overline{1})$ faces is due to their different growth rates which are related to their different molecular structure. As described by Abbona, Calleri and Ivaldi [15] the $\mathrm{NH}_{4}{ }^{+}$groups terminate the (001) surface, while the groups $\mathrm{PO}_{4}{ }^{3-}$ and $\mathrm{Mg}\left(\mathrm{H}_{2} \mathrm{O}\right)_{6}^{2+}$ terminate the $(00 \overline{1})$ surface (Fig. $6 \mathrm{~b})$. Therefore, it is possible that the growth of the $(00 \overline{1})$ surface is slowed down by binding the ions, which outcrop this surface by ions present in the solution of urine or the ions related to bacteria existence. This may happen because the surface of bacterial cells usually demonstrates anionic character and therefore they have ability to trap positive ions from the surrounding environment [23]. In the case of $P$. mirabilis, it is shown that capsular polysaccharide and lipopolysaccharide of these microorganisms have the ability to bind the $\mathrm{Ca}^{2+}$ and $\mathrm{Mg}^{2+}$ ions $[24,25]$. Strictly speaking, the polysaccharides which represent the outermost structures of P.mirabilis cell show such ability. On this basis, we speculate that the structure and anionic nature of $P$. mirabilis polysaccharides slow down the growth of the $(00 \overline{1})$ surface by binding the $\mathrm{Mg}^{2+}$ ions which terminate this surface. The growth of the (001) surface is not slowed down and therefore it grows freely, and consequently it is much smaller in comparison with the $(00 \overline{1})$ surface. As a consequence, the crystal takes coffin-like habit with large $(00 \overline{1})$ surface at the bottom and small (001) surface at the lid. In the case of absence of bacteria, the growth rate of the $(00 \overline{1})$ surface may be slowed down by binding other ions present in the urine. However, in this case the crystals of struvite, besides coffin-like habits, display other habits as illustrated in Fig. 3b-f. Therefore, in this case, it seems that such a binding of ions happens rarely.

As we stated earlier the changes in $\mathrm{pH}$ value induced transformations in the crystal morphology and habit. At high $\mathrm{pH}$ value, twins and dendrite-like structures appear as illustrated in Fig. 1 middle and right columns, respectively. These dendrites are also porous with very characteristic
Fig. 6 Schematic representation of struvite morphology and habits characteristic for growth from artificial urine with the presence of $P$. mirabilis at relatively low $\mathrm{pH}$ value $(\mathbf{a}, \mathbf{b})$ and high value of $\mathrm{pH}$, approximately equal to $9.5(\mathbf{c}, \mathbf{d})$. The crystals of the morphology in $\mathbf{c}$ and $\mathbf{d}$ are subunits of larger dendritic structures shown in Fig. 2, middle and right columns. This morphology was drawn on the basis of experimentally observed faces and the $(h k l)$ indices are suggested based on these observations and angular measurements only

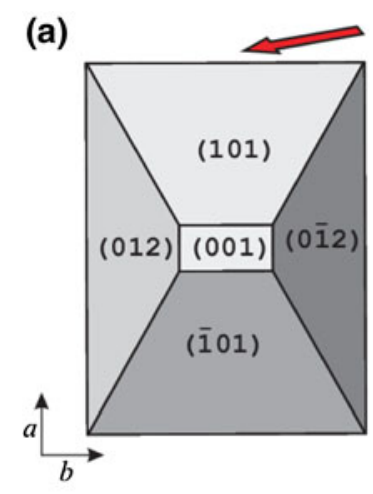

at the bottom: (001) (b)

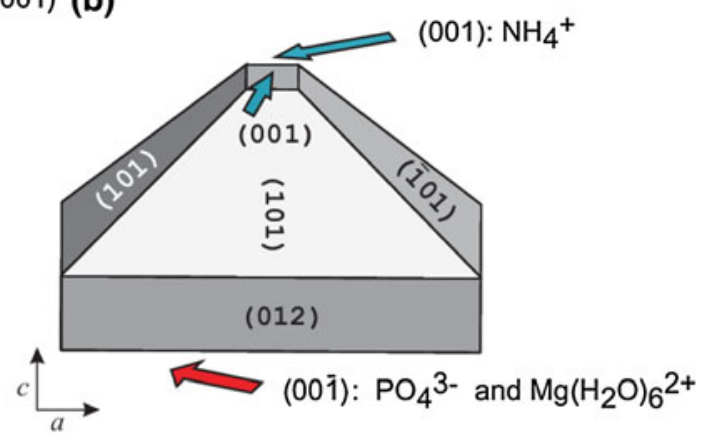

(c)

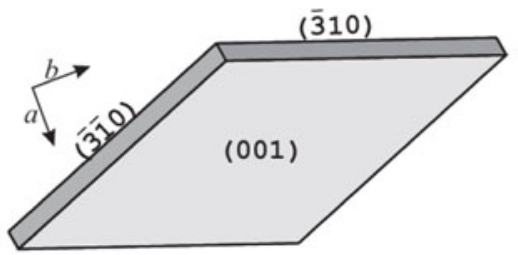

(d)

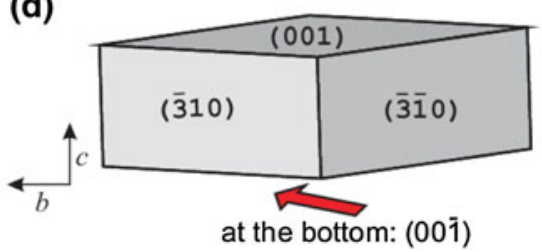


surface pattern (Fig. 2, panels M3 and R4) as discussed in the previous subsection. However, the experimental observations imply that dendrite-like structures correspond to the repetition in three dimensions of the same unit of rhombohedral habit (Fig. 2, panels M1, M2), not coffinlike. This suggests that at high $\mathrm{pH}$ (high supersaturation) the habit of primary crystals is modified. It seems that at high $\mathrm{pH}$, the morphology is composed by rhombohedral column such as $\{310\}$ (Fig. 6c) and probably by the (001) and $(00 \overline{1})$ faces. The exact morphology with Miller indices of this type of crystal is unclear. The morphology and Miller indices presented in Fig. 6c, d are suggested on the basis of experimental observation and angle measurements only. These rhombohedral crystals are well aligned with respect to the next crystal and arranged layer-on-layer forming the dendritic structure of X-shaped or with the trunk distinguished. It is possible that this modification in primary crystal is also bacteria-mediated. However, it also possible that in such a structuration the polar character of $c$ axis of struvite plays important role. The (001) surface is rich in $\mathrm{NH}_{4}{ }^{+}$groups, while the $(00 \overline{1})$ surface is rich in the $\mathrm{PO}_{4}{ }^{3-}$ and $\mathrm{Mg}\left(\mathrm{H}_{2} \mathrm{O}\right)_{6}{ }^{2+}$ groups, so $c$ axis is dipole axis. Therefore, it is suggested that the structuration is due to strong dipole-dipole interaction.

To develop and fully explain biological and physical mechanisms of struvite structuration and morphology and habit modification, the growth process and bacteria should be considered as complex dynamical system. The first stage of the understanding these mechanism is to determine which components (proteins, polysaccharides, metabolites) of the system interact. This is a goal of our present research in this field.

\section{Conclusions}

Struvite grown from solution of artificial urine in the presence of $P$. mirabilis, at first stage of growth, take hemimorphic coffin-like habit with large $(00 \overline{1})$ face and small (001) face. From the comparison of this result with the results of the control experiments without bacteria, it can be concluded that in the case of absence of bacteria, the crystals in most cases take also the coffin-like habits, but the crystals of other habits are also observed. In addition, in the case of absence of bacteria, the number of crystals is increased and so is their size. In the case of presence of bacteria, it is suggested that the anionic character of the surface of $P$. mirabilis cells and their ability to bind $\mathrm{Mg}^{2+}$ ions slow down the growth of the $(00 \overline{1})$ face by binding the $\mathrm{Mg}^{2+}$ ions which outcrop this face. Consequently, this face increases in size, which leads to different extension of the $(001)$ and $(00 \overline{1})$ faces. This result shows a possible complex relationship between nature of bacterial cells and metal binding.

At higher $\mathrm{pH}$, single crystals are observed rarely, and instead twins and dendritic structures appear. Primary crystals of dendritic structures are not coffin-like, but they are rhombohedral. This suggests that at higher $\mathrm{pH}$, the habit of primary crystals is modified. The mechanism of such changes is not clearly understood. However, it seems that polar character of $c$ axis of struvite and dipole-dipole interaction may play an important role in this modification.

Single crystals as well twins and dendritic structures show characteristic structuration, which turns out to be only surface pattern. The results do not confirm that the struvite is mesocrystal. However, the internal structure shows porous nature with characteristic tubular pores. The presence of such pores may suggest possible interaction of struvite stone with urine. In particular, the porosity may facilitate the adhesion of bacteria and biofilm development in which bacteria are resistant to antibiotic therapy and immune defense mechanisms.

Acknowledgments This work has been supported by the Polish Ministry of Science and Higher Education (MNiSzW), Grant No. N N202 033437. One of us (Jolanta Prywer) is very grateful to Prof. Helmut Cölfen (University of Konstanz, Germany) for valuable discussion on the specific structuration of struvite. Jolanta Prywer is indebted to Prof. Keshra Sangwal (Technical University of Lublin, Poland) for his constructive comments. Jolanta Prywer is also grateful to Mr. Włodzimierz Wypych (Technical University of Lodz, Poland), for the execution of SEM images of struvite crystals.

Open Access This article is distributed under the terms of the Creative Commons Attribution License which permits any use, distribution, and reproduction in any medium, provided the original author(s) and the source are credited.

\section{References}

1. Bhuiyan MIH, Mavinic DS, Koch FA (2008) Chemosphere 70:1347-1356

2. Doyle JD, Simon AP (2002) Water Res 36:3925-3940

3. Gaterell MR, Gay R, Wilson R, Gochin RJ, Lester JN (2000) Environ Technol 21:1067-1084

4. Weil M (2008) Cryst Res Technol 43:1286-1291

5. Bichler KH, Eipper E, Naber K, Braun V, Zimmermann R, Lahme S (2002) Int J Antimicrob Agents 19:488-498

6. Chauhan ChK, Joshi MJ (2011) J Cryst Growth. doi:10.1016/ j.jcrysgro.2011.11.008

7. Website of e-medicine: http://emedicine.medscape.com/article/ 439127. Accessed 30 Aug 2011

8. Singh M, Chapman R, Tresidder GC, Blandy J (1973) Br J Urol 45:581-585

9. Wojewski A, Zajączkowski T (1974) Int Urol Nephrol 5:249-260

10. Prywer J, Torzewska A (2010) Cryst Res Technol 45:1283-1289

11. Chen L, Shen Y, Xie A, Huang F, Zhang W, Liu S (2010) Cryst Growth Des 10:2073-2082

12. Cölfen H, Antonietti M (2005) Angew Chem Int Ed 44:55765591 
13. Griffith DP, Musher DM, Itin C (1976) Invest Urol 13:346-350

14. Prywer J, Torzewska A (2009) Cryst Growth Des 9:3538-3543

15. Abbona F, Calleri M, Ivaldi G (1984) Acta Cryst Section B 40:223-227

16. Dominick MA, White MR, Sanderson TP, Van Vleet T, Cohen SM, Arnold LE, Cano M, Tannehill-Gregg S, Moehlenkamp JD, Waites CR, Schillin BE (2006) Toxicol Pathol 34:903-920

17. Wierzbicki A, Sallis JD, Stevens ED, Smith M, Sikes CS (1997) Calcif Tissue Int 61:216-222

18. Rakovan J (2007) Rocks Miner 82:329-333

19. Bazin D, Andre G, Weil R, Matzen G, Emmanuel V, Carpentier X, Daudon M (2012) Urology 79:786-790
20. Daudon M, Bazin D, Gilles A, Jungers P, Cousson A, Chevallier P, Vrone E, Matzen GJ (2009) Appl Crystallogr 42:109-115

21. Piechota J, Prywer J, Torzewska A (2011) Comp Methods Biomech Biomed Eng. doi:10.1080/10255842.2011.593175

22. Cohen NP, Whitfield HN, World J (1993) Urology 11:13-18

23. Donot F, Fontana A, Baccou JC, Schorr-Galindo S (2012) Carbohydr Polym 87:951-962

24. Torzewska A, Stączek P, Różalski A (2003) J Med Microbiol $52: 471-477$

25. Dumanski AJ, Hedelin H, Edin-Liljegren A, Beauchemin D, McLean RJC (1994) Infect Immun 62:2998-3003 